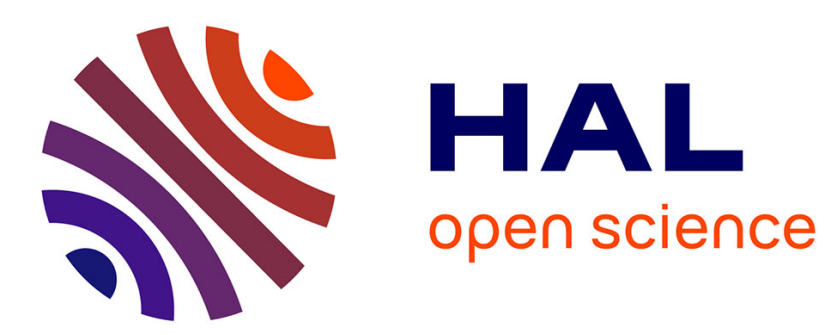

\title{
HIGH QUALITY FACTOR COPPER INDUCTORS INTEGRATED IN DEEP DRY ETCHED QUARTZ SUBSTRATES
}

\author{
C. Leroy, M. Pisani, C. Hibert, D. Bouvet, M. Puech, A.M. Ionescu
}

\section{- To cite this version:}

C. Leroy, M. Pisani, C. Hibert, D. Bouvet, M. Puech, et al.. HIGH QUALITY FACTOR COPPER INDUCTORS INTEGRATED IN DEEP DRY ETCHED QUARTZ SUBSTRATES. DTIP 2006, Apr 2006, Stresa, Lago Maggiore, Italy. 5 p. hal-00189280

\section{HAL Id: hal-00189280 \\ https://hal.science/hal-00189280}

Submitted on 20 Nov 2007

HAL is a multi-disciplinary open access archive for the deposit and dissemination of scientific research documents, whether they are published or not. The documents may come from teaching and research institutions in France or abroad, or from public or private research centers.
L'archive ouverte pluridisciplinaire HAL, est destinée au dépôt et à la diffusion de documents scientifiques de niveau recherche, publiés ou non, émanant des établissements d'enseignement et de recherche français ou étrangers, des laboratoires publics ou privés. 


\title{
HIGH QUALITY FACTOR COPPER INDUCTORS INTEGRATED IN DEEP DRY ETCHED QUARTZ SUBSTRATES
}

\author{
C. Leroy ${ }^{1}$, M.B. Pisani ${ }^{1,2}$, C. Hibert ${ }^{2}$, D. Bouvet ${ }^{1}$, M. Puech ${ }^{3}$, A.M. Ionescu ${ }^{1}$ \\ ${ }^{1}$ Electronics Laboratory (LEG) and \\ ${ }^{2}$ Center of Micro and Nanotechnology (CMI) \\ Institute of Microelectronics and Microsystems (IMM) \\ Swiss Federal Institute of Technology (EPFL), Station 17, Lausanne CH-1015, Switzerland \\ ${ }^{3}$ Alcatel Vacuum Technology, 98 av. de Brogny, Annecy F-74000, France
}

\begin{abstract}
This paper reports on an inductor fabrication method capable to deliver high quality factor (Q) and high self resonance frequency (SRF) devices using quartz insulating substrates and thick high-conductivity copper lines. Inductors are key devices in RF circuits that, when fabricated on traditional semiconductor substrates, suffer from poor RF performances due to thin metallization and substrate related losses. Many previous works revealed that RF performances are strongly dependent on the limited metallization thickness and on the conductivity of the substrate. In this paper we demonstrate a new fabrication process to improve the $\mathrm{Q}$ factor of spiral inductors by patterning thick high conductive metal layers directly in a dielectric substrate. Moreover, we develop and validate accurate equivalent circuit modeling and parameter extraction for the characterization of the fabricated devices.
\end{abstract}

\section{INTRODUCTION}

Modern applications using RF ICs demand higher working frequencies, low noise and low power consumption, which require high Q-factor and high SRF passive components.

Our study concerns integrated inductors for which low RF performances limit their application in RF ICs. Typical values are $\mathrm{Q}_{\mathrm{MAX}}<10-15$, with a peak bellow 2 $\mathrm{GHz}$ and self-resonant frequencies below $3-5 \mathrm{GHz}$ [1]. The origin of their limited performances is well known and reported: inductors mainly suffer from substrate related RF losses due to low-resistivity underneath substrate, low metal tracks conductivity due to thin layers resistive losses and capacitive parasitics due to spiral tracks / substrate coupling.

Many works have already been done and a lot of solutions have been investigated to increase these performances. For reducing substrate-related losses, high- resistivity silicon or SOI substrates have been used [2], insulating the inductor from the silicon substrate [3]. Etching a cavity underneath the inductor have also been investigated [4].

Even if inductors with reasonable Q factors and resonant frequencies can be manufactured on top of low-resistivity silicon wafers [5], covering most of the telecommunication applications, the nature of the substrate remains a recurrent limitation. In the early 2000 , Yoon et al. [6] investigated the RF performances of the same inductor design fabricated on both silicon and glass substrates. On-glass inductor provided a significant increase in both quality factor $(45 \%)$ and self resonant frequency (2.5 times higher) due to a relatively large decrease in the parasitic capacitance to the substrate.

We used new inductive coupled plasma (ICP) etcher dedicated to dielectrics anisotropic deep dry etching in order to explore a new technique based on patterning the inductor directly in a quartz substrate. The main advantage of this technique is the high resistivity of the quartz $\left(2.10^{14} \Omega \mathrm{cm} @ 20^{\circ} \mathrm{C}\right)$, which reduces dramatically the substrate-related RF losses.

\section{FABRICATION PROCESS}

Fig. 1 shows a schematic cross section view of the technology steps used to fabricate thick copper spiral inductors embedded in a quartz substrate. A $2 \mu \mathrm{m}$ sputtered amorphous silicon film is used as hard mask for the etching of the quartz (fig. 1a). This a-Si hard mask is patterned by thin-resist photolithography followed by a $\mathrm{SF}_{6} / \mathrm{C}_{4} \mathrm{~F}_{8}$ dry plasma etching step (fig. 1b). The quartz substrate is then patterned by $\mathrm{C}_{4} \mathrm{~F}_{8} / \mathrm{CH}_{4} / \mathrm{Ar}$ plasma etching step performed in a state-of-the-art Alcatel AMS 200 DSE ICP dry etcher (fig. 1c). After stripping off the amorphous silicon mask (fig. 1d), the quartz mould is cleaned in a piranha bath $\left(\mathrm{H}_{2} \mathrm{SO}_{4} / \mathrm{H}_{2} \mathrm{O}_{2}\right)$ and receives $0.1 \mu \mathrm{m}$ sputtered chromium as adhesion layer and a $0.2 \mu \mathrm{m}$ sputtered copper as seed layer (fig. 1e). The mould 
is filled out with $4.8 \mu \mathrm{m}$ of high conductive electroplated copper (resistivity $=2.0 \mu \Omega \mathrm{cm}$, fig. 1f). Copper lines are then defined by a damascene approach using a highremoval rate chemical-mechanical polishing receipt
(CMP) [7] (fig. 1g). The CMP stops at the top chromium layer which is cleared in very selective chromium to copper wet etch bath (fig. 1h). (a)

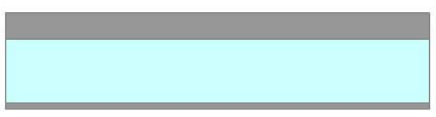

(b)

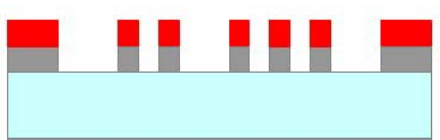

(c)

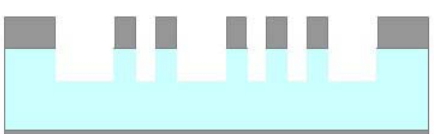

(d)

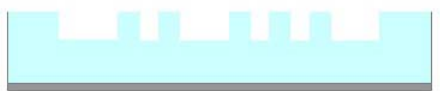

(e)

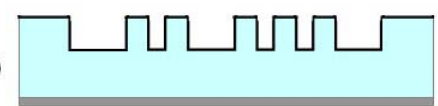

(f)

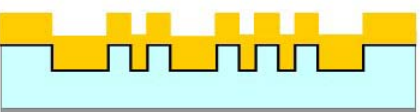

(g)

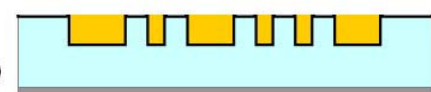

(h)

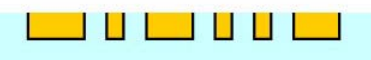

(i)

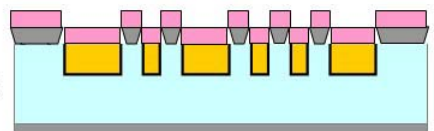

(j)

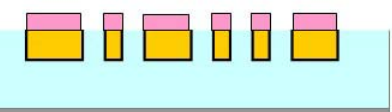

(k)

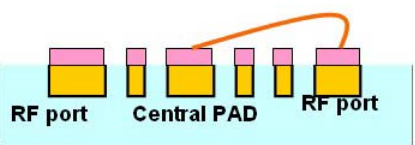

a-Si

$-\mathrm{Cr} / \mathrm{Cu}$

ECP Cu Ti $\square$ TI

Fig. 1: Schematic cross section view of the coil fabrication process flow: (a) a-Si deposition (PVD), (b) a-Si dry etching, (c) Quartz dry etching, (d) a-Si mask strip, (e) Adhesion and seed layers deposition ( $\mathrm{Cr} / \mathrm{Cu}$, PVD), (f) Cu electroplating, (g) Chemical mechanical polishing, (h) Top Cr wet etching, (i) Lithography and protection layer deposition (Ti / Al), (j) Lift-off, (k) Gold wire bonding.
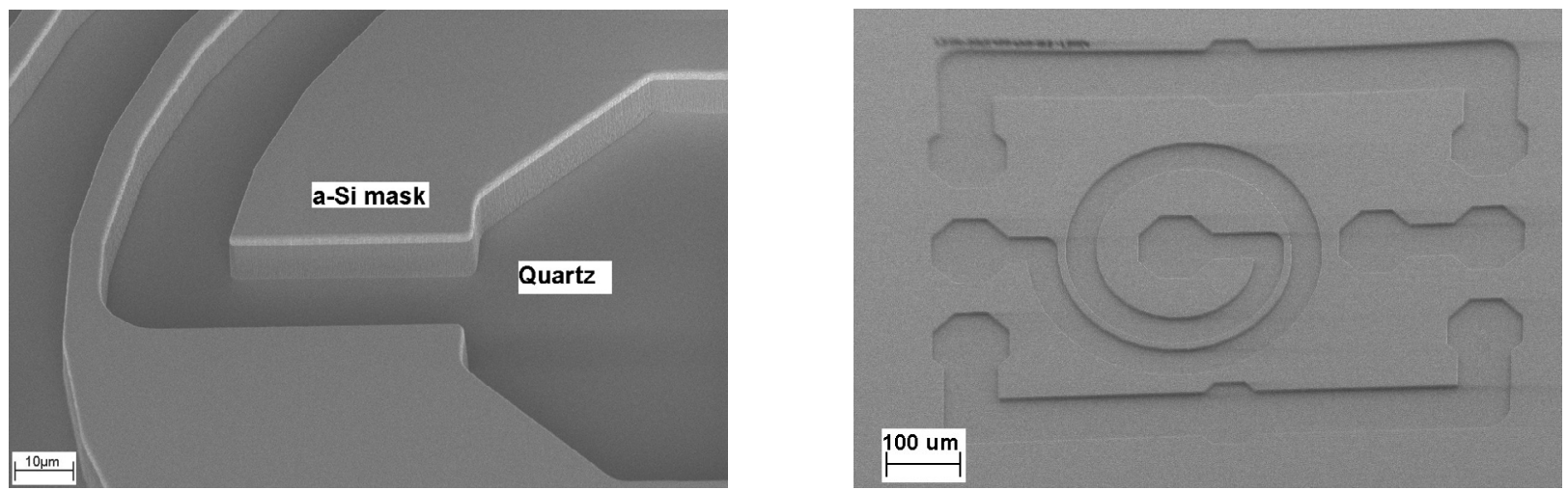

Fig. 2: SEM closed view of a $4 \mu \mathrm{m}$ deep dry etched quartz inductor mould (40 $\mu \mathrm{m}$ track width and $8 \mu \mathrm{m}$ track spacing).

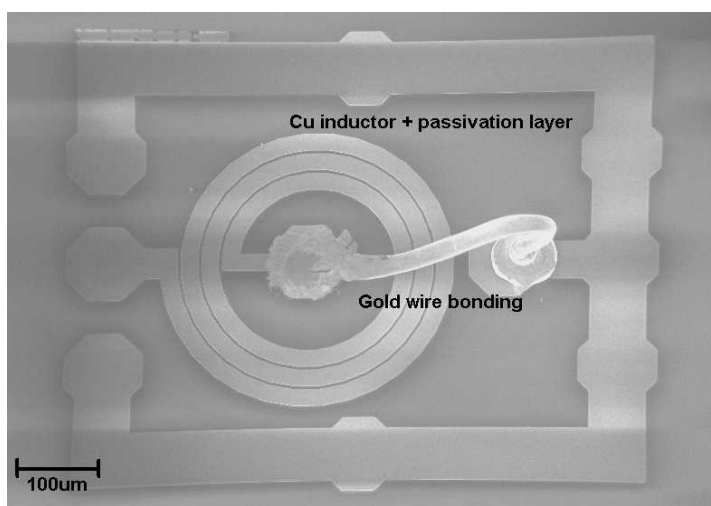

Fig. 3: View of a fabricated 3-turn circular spiral inductor ( $400 \mu \mathrm{m}$ outer diameter, $40 \mu \mathrm{m}$ track width, $8 \mu \mathrm{m}$ track spacing). 
A protection layer is then defined in order to avoid copper oxidation and to have good electrical contacts to the devices. The protection is composed of $0.2 \mu \mathrm{m}$ titanium and $0.6 \mu \mathrm{m}$ of aluminum layers deposited successively in the same multi-target evaporator system, which avoids the first film to be exposed to air (fig. 1i). The protection layer is patterned by lift-off process, using reversal thin-resist (fig. 1j). Finally, connections are established by bonding a $25 \mu \mathrm{m}$ diameter gold wire between the inductor central pad and the lateral RF port (fig. 1k).

Fig. 2 shows scanning electron microscopy (SEM) pictures of a quartz etched mould. $\mathrm{C}_{4} \mathrm{~F}_{8} / \mathrm{CH}_{4} /$ Ar plasma etching is a very selective process $(>20)$ that provides very vertical walls [8]. Quartz mould is also very well defined.

A SEM photo of a final fabricated device can be seen in fig. 3 .

\section{RESULTS}

RF electrical characterization was performed using full 2-port S-parameter measurements in a microprober equipped with an HP 8719D vector network analyzer and Cascade Microtech RF ground-signal-ground probes (GSG). The RF setup is calibrated in the range of frequencies from 0.05 to $13.5 \mathrm{GHz}$ using an Impedance Standard Substrate with SOLT references (short-circuit, open, load and thru). Measured S-parameter data are transformed into Y-parameters and inductance and quality factor of the devices are calculated from the equivalent 1port impedance of the device as [1]:

$$
\begin{gathered}
L=\frac{\operatorname{imag}\left(\frac{1}{y_{11}}\right)}{2 \pi f} \\
Q=\frac{\operatorname{imag}\left(\frac{1}{y_{11}}\right)}{\operatorname{real}\left(\frac{1}{y_{11}}\right)}
\end{gathered}
$$

Where $\mathrm{L}$ is the inductance, $\mathrm{Q}$ is the quality factor, $\mathrm{f}$ is the measurement frequency and $1 / y_{11}$ is the equivalent complex impedance of port 1 when port 2 is connected to the ground [1]. These formulas are commonly used for isolated inductors working below the resonant frequency.
The resonant frequency is defined when the expression for Q (eq. 2) goes to 0.

In this paper, we analyze 2 devices of 3.8 and $9.0 \mathrm{nH}$ nominal inductances that have been fabricated and characterized in the $0.05-13.5 \mathrm{GHz}$ frequency range. Dimensions and calculated inductance of each device are summarized in table 1. Expected inductance values are calculated following the current sheet method presented in [9]. The thicker layer used in this work with respect to [9] explains a reduction of a few percent in the inductance values with respect to the predicted ones (inductance decreases with both increasing track width and thickness, but must of practical formulae neglect the thickness dependency).

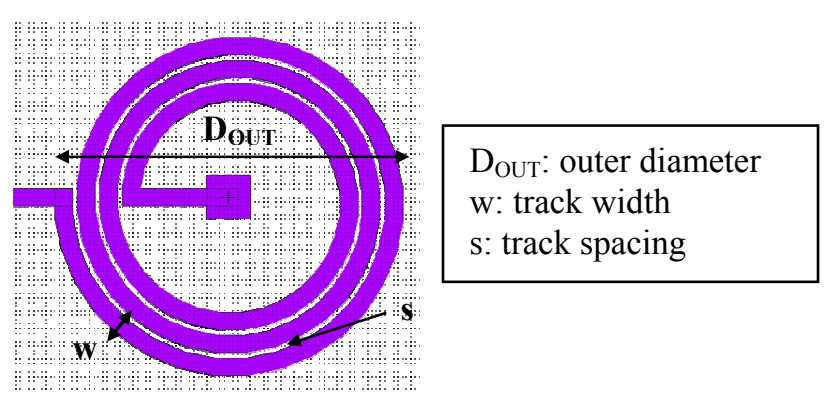

Fig. 4: Schematic view of a 3-turn circular inductor and its main geometrical parameters.

\begin{tabular}{|c|c|c|}
\hline & $\mathbf{L}_{\mathbf{1}}$ & $\mathbf{L}_{\mathbf{2}}$ \\
\hline $\mathbf{D}_{\text {OUT }}(\boldsymbol{\mu \mathbf { m } )})$ & 800 & 800 \\
\hline $\mathbf{w}(\boldsymbol{\mu m})$ & 20 & 40 \\
\hline $\mathbf{s}(\boldsymbol{\mu \mathbf { m }})$ & 12 & 12 \\
\hline form & octagonal & circular \\
\hline \# of turns & 1.5 & 3 \\
\hline $\mathbf{L}_{\text {(PREDICTED) }}$ & $4.3 \mathrm{nH}$ & $9.3 \mathrm{nH}$ \\
\hline $\mathbf{L}_{\text {(MEASURED) }}$ & $3.8 \mathrm{nH}$ & $9.0 \mathrm{nH}$ \\
\hline
\end{tabular}

Table 1: Dimensions and inductances of two analyzed inductors.

Figs. 5 and 6 show respectively the extracted L-values (eq. 1) and Q-factors (eq. 2) of these 2 inductors.

We have used a broadband RLC equivalent circuit of a spiral inductor in order to model the measured parameters. Fig. 7 shows the equivalent 1-port circuit [1] and the values of the parameters extracted from the measurements using a dedicated procedure (non-linear least squares fit on the S-parameter and on impedance data). The L-Q plots for this model are also shown in figs. 5 and 6 . 


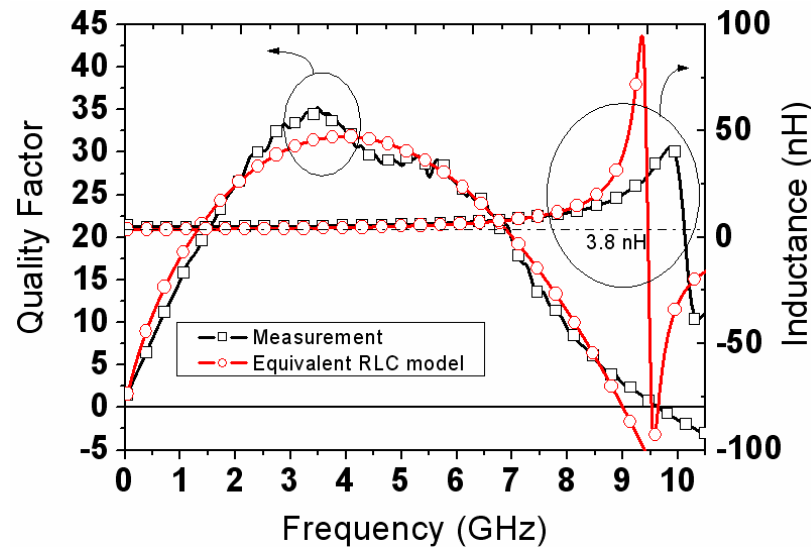

Fig. 5: Extracted inductance (eq. 1) and Q-factor (eq. 2) vs. frequency for the 3.8-nH device $\left(\mathrm{L}_{1}\right)$.

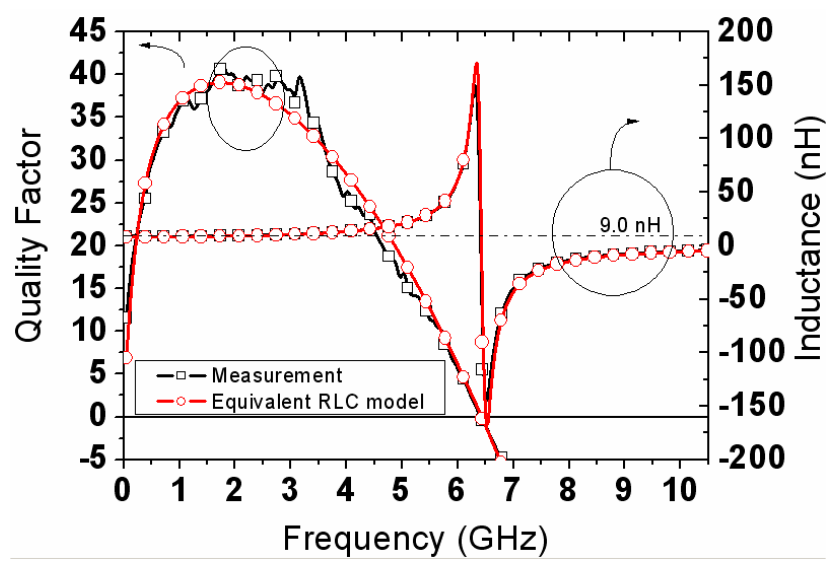

Fig. 6: Extracted inductance (eq.1) and Q- factor (eq.2) vs. frequency for the $9.0 \mathrm{nH}$ circular inductor $\left(\mathrm{L}_{2}\right)$.

In the model of fig. $7, \mathrm{R}_{\mathrm{S}}$ accounts for the series resistance of the metal tracks and is dependent of the frequency in the form $R_{S}(f)=R_{D C}+a \sqrt{f}+b f$ where $\mathrm{R}_{\mathrm{DC}}$ is the low frequency resistance and $\boldsymbol{a}$ and $\boldsymbol{b}$ are constants depending on the device geometry that accounts for the skin and proximity effects. These effects increase the resistance as function of the frequency [10]. $C_{P}$ is the parasitic parallel capacitance that comes mainly from the capacitive coupling between adjacent inductor tracks. $\mathrm{C}_{\mathrm{INS} 1}$ and $\mathrm{C}_{\mathrm{SUB} 1}$ accounts for the parasitic capacitances between the measurement ports and between the spiral tracks and the backside ground of the wafers. $R_{\text {SUB1 }}$ accounts for the resistive losses in the substrate, due to the substrate conductivity as well as to eddy currents induced in the substrate by the magnetic field of the inductor. Its value ranges from typically some ohms to hundreds of ohms when the spiral is designed on top of low-resistivity substrates. This resistance decreases the peak quality factor as well as the self resonant frequency. For our devices, the contribution of the substrate is reduced to its minimum by the use of the insulating quartz substrate, and only the $\mathrm{C}_{\mathrm{P}}$ value needs to be considered to produce an accurate equivalent circuit model.

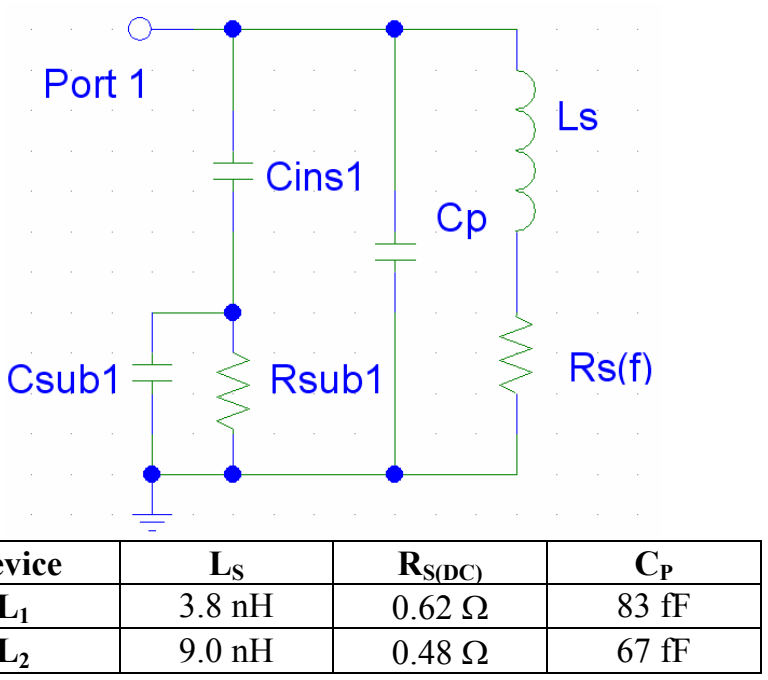

Fig. 7: Equivalent broadband RLC model of a spiral inductor [1] and extracted values for $\mathrm{L}_{1}$ and $\mathrm{L}_{2}$ devices $\left(\mathrm{C}_{\mathrm{INS} 1}, \mathrm{R}_{\mathrm{SUB} 1}\right.$ and $\mathrm{C}_{\mathrm{SUB} 1}$ substrate parameters are negligible).

Fig. 5 shows the electrical performance and RLC fit for the 3.8-nH inductor. We observed a peak quality factor of 35 at $3.5 \mathrm{GHz}$ and a self resonance frequency of $9 \mathrm{GHz}$. Fig. 6 shows the electrical performances and RLC fit for the 9.3-nH inductor. Measured peak quality factor is 40 at $2.1 \mathrm{GHz}$ and resonant frequency is $6.5 \mathrm{GHz}$.

It should be pointed that the fabricated devices exhibit a broadband Q-behavior, with Q exceeding 20 in the range of 1 to $5 \mathrm{GHz}$, enabling the use of such devices in multiband circuits, covering a significant number of telecommunication standards, including GSM, UMTS and WLAN. The achieved performances in terms of $\mathrm{Q}_{\mathrm{PEAK}}$ and SRF are in the current state-of-the-art for integrated inductors $[5,11]$.

\section{CONCLUSION}

We developed an innovative fabrication process of passive devices directly embedded in an insulating substrate. This technique uses a state-of-the-art Alcatel AMS 200 DSE ICP dry etcher that enables to pattern deep trenches in quartz substrates and to fabricate devices using a reduced number of masks. The major advantage of this technique is to significantly decrease the RF losses due to parasitic capacitance by using a dielectric as substrate. We fabricated and characterized integrated spiral inductors with high RF performances (peak quality factor in excess of 30 around $2 \mathrm{GHz}$ and self resonant frequency superior 
to 6 and $9 \mathrm{GHz}$ ) using a thick high conductivity copper / quartz fabrication process.

The broadband Q-behavior of the fabricated components enables the use of them in telecommunication applications, particularly in multi-standard circuits that can operate at different standards in the $1-6 \mathrm{GHz}$ range (GSM, UMTS and WLAN).

\section{ACKNOWLEDGMENTS}

The authors thank the IST Wide-RF project (IST-200133286 ), the Swiss OFES project 01.0308 and the IST MIMOSA project (IST-2002-507045) for funding. We thank Mr. Giancarlo Corradini from the EPFL-LPM (Laboratoire de Production Microtechnique) for providing the gold wire-bonding services. Many thanks are due to the EPFL-CMI staff for the clean room facilities access and supplied technical support.

\section{REFERENCES}

[1] C.P. Yue and S.S. Wong, "Physical Modeling of Spiral Inductors on Silicon", IEEE Transactions on Electron Devices, vol. 47 , pp. 560-568, 2000.

[2] A.C. Reyes, S.M. El-Ghazaly, S. Dorn, M. Dydyk, D.K. Schroder and H. Patterson, "High-resistivity silicon as a microwave substrate," Proceedings Electronic Components and Technology Conference, pp. 382-391, 1996.

[3] B.K. Kim, B.K. Ko and K. Lee, "Monolithic planar RF inductor and waveguide structures on silicon with performance comparable to those in GaAs MMIC", IEDM Tech. Digest, pp. 717-720, 1995.

[4] M. Ozgur, M. Zaghloul and M. Gaitan, "High Q backside Micromachined CMOS inductors", IEEE International Symposium on Circuits and Systems, vol.2, pp. 577-580, 1999.

[5] H. Lakdawala, X. Zhu, H. Luo, S. Santahannan, L.R. Carley and G.K. Fedder, "Micromachined high-Q inductors in a 0.18$\mu \mathrm{m}$ copper interconnect low-k dielectric CMOS process", IEEE Journal of Solid State Circuits, vol. 37, pp. 394-403, 2002.

[6] J.B. Yoon, B.K. Kim, C.H. Han, E. Yoon and C.K Kim, "Surface micromachining Solenoid On-Si and On-Glass Inductors for RF Applications", IEEE Electron Devices Letters, vol. 20, n. 9, pp. 487-489, 1999.

[7] M.B. Pisani, C. Hibert, D. Bouvet, P. Beaud and A.M. Ionescu, "Copper/polyimide fabrication process for above-IC integration of high quality factor inductors", Microelectronics Engineering, vol. 73-74, pp. 474-479, 2004.

[8] M. Pavius, C. Hibert, P. Flückiger and P. Renaud, "Profile angle control in $\mathrm{SiO}_{2}$ deep anisotropic dry etching for MEMS fabrication", Proc. MEMS 2004, pp. 669-672, 2004.
[9] S. Moham, M.M. Hershenson, S.P. Boyd and T.H. Lee, "Simple accurate expression for planar spiral inductances", IEEE Journal of Solid State Circuits, vol. 34, pp. 1419-1424, 1999.

[10] I. Bahl, "Lumped Elements for RF and Microwave Circuits", Artech House, Boston, 2003.

[11] G.J. Carchon, W. de Raedt and E. Beyne, "Wafer-level packaging technology for high-Q on-chip inductors and transmission lines" IEEE Transactions on Microwave Theory and Techniques, vol. 52, pp. 1244-1251, 2004. 